\title{
Homodicentric chromosomes: a distinctive type of dicentric chromosome*
}

\author{
BRIAN E WARD, CYNTHIA M BRADLEY, JANE B COOPER, \\ AND ARTHUR ROBINSON \\ From the National Jewish Hospital and Research Center/National Asthma Center; and \\ Department of Biophysics and Genetics of the University of Colorado School of Medicine, Denver, \\ Colorado, USA.
}

SUMMARY This report describes two patients with a distinctive type of dicentric autosomal chromo- $\overrightarrow{0}$ some formed by breakage and union between homologous chromosomes. These stable chromosomes $\stackrel{+}{\circ}$ possess two $\mathrm{C}$ bands, implying the presence of two centromeric regions. The first child, evaluated ${ }^{\circ}$ for dysmorphic features, was shown to have an abnormal chromosome 16, designated as $46, \mathrm{XX}$, 7 $-16,+\operatorname{dic}(16)($ pter $\rightarrow$ cen $\rightarrow q 22:: p 11 \rightarrow q$ ter $)$. The second case is a child with the typical features of $\frac{\mathbb{D}}{O}$ trisomy 18 whose karyotype is designated as $46, \mathrm{XX},-18,+\operatorname{dic}(18)(\mathrm{qter} \rightarrow \mathrm{p} 11 \cdot 1:: \mathrm{p} 11 \cdot 3 \rightarrow$ cen $\rightarrow \mathrm{qter})$. The stability of these chromosomes is presumably the result of centromere suppression and associated premature centromere division of the suppressed centromere. The possible mechanism $\overrightarrow{0}$ of formation of these homodicentric chromosomes is presented, and a comparison is made between $\stackrel{\infty}{-}$ them and three patients with dicentric $\mathrm{X}$ chromosomes.

The identification of stable dicentric chromosomes has been simplified by the use of $C$ banding. Structurally abnormal sex chromosomes, as well as Robertsonian translocations, often possess two $\mathrm{C}$ bands, implying the presence of two centromeric regions. ${ }^{1-3}$

This report describes two cases representing a new type of dicentric chromosome with two $\mathrm{C}$ band regions formed by meiotic breakage and subsequent joining between homologous chromosomes. These homodicentrics will be compared to the three types of structurally abnormal $\mathbf{X}$ chromosomes proposed by $\mathrm{Hsu}$ et $\mathrm{al}^{1}$ : an isochromosome, an isodicentric isochromosome $\mathrm{X}$ with two $\mathrm{C}$ band regions (type 1 ), and an asymmetrical isodicentric $\mathrm{X}$ chromosome with two $C$ band regions (type 2 ).

\section{Methods}

Peripheral lymphocyte cultures were established and harvested in the usual fashion. ${ }^{45}$ Fibroblast cultures were also established on one patient (case 2$){ }^{6}$ All

\footnotetext{
* This work was supported in part by grants from The Genetic Foundation, Inc, The Boettcher Foundation, and The Henry J Kaiser Family Foundation.

Received for publication 10 March 1980
}

samples were stained using $\mathrm{GTG},{ }^{7} \mathrm{CBG},{ }^{8}$ and $\mathrm{QFQ}^{9}$ banding.

\section{Case reports}

Case 1 was the female offspring of an uncomplicated term pregnancy. At birth, height and head circumference were at the 50th centile while weight was below the 3rd centile. Birth asphyxia and meconium aspiration were present. Evaluation at 10 months of $\frac{5}{3}$ age revealed the following abnormalities: head circumference and weight below the 3 rd centile, $\frac{3}{3}$ hypotonia, right facial hemihypertrophy, persistent ductus arteriosus, bilateral transpalmar creases, $\stackrel{\circ}{\supset}$ abnormal gross motor movements, and develop- $\rightarrow$ mental delay.

Case 2 was the female offspring of an 8 month gestation. At birth numerous congenital abnor- $N$ malities were present, including epicanthic folds, $\bigcirc$ bilateral cleft lip, redundant skin around the neck, $\omega$ absent right clavicle, rib abnormalities, and rockerbottom feet. The patient died at 6 weeks of age witho the clinical diagnosis of trisomy 18. Blood and $\mathbb{D}$ tissue samples were obtained upon death.

Case 3 was referred at the age of 20 years with a ${ }^{\circ}$ history of primary amenorrhoea, short stature $\frac{\mathrm{D}}{\mathbb{\Phi}}$ $(145 \mathrm{~cm})$, cubitus valgus, immature genitalia, and short fourth metacarpals. 


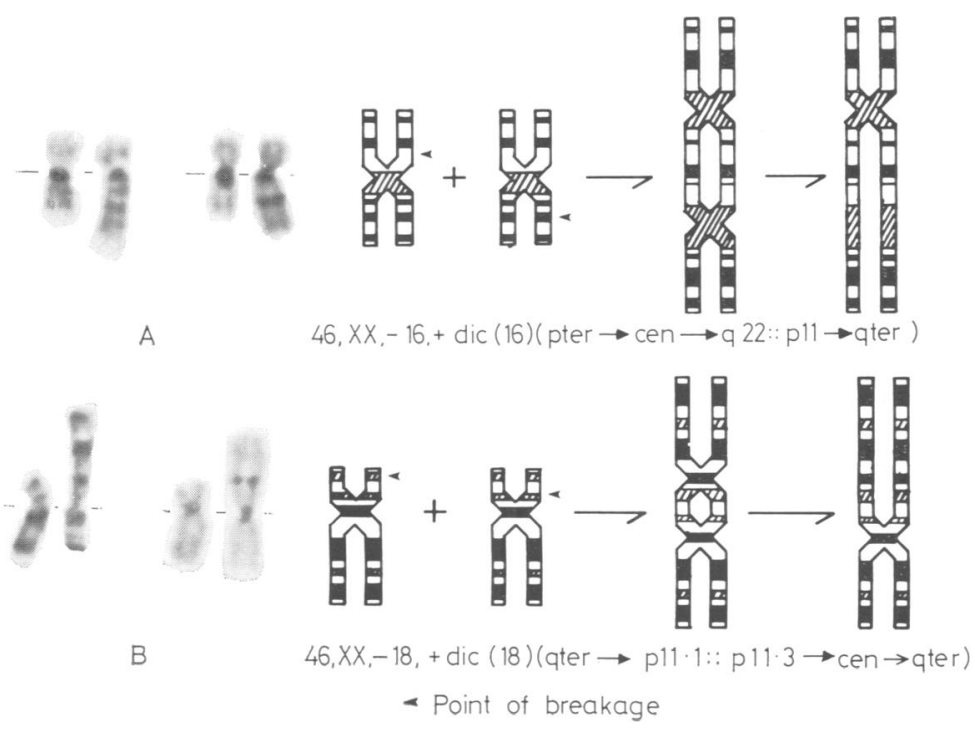

FIG 1 Homodicentric chromosomes and presumed mechanism of formation. (A) case 1; (B) case 2.

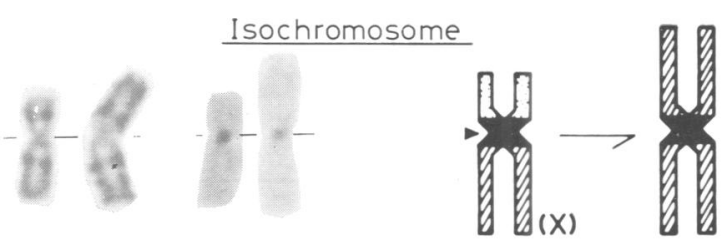

A $\quad$ 46, $X, i(X)($ qter $\rightarrow$ cen $\rightarrow$ qter $)$

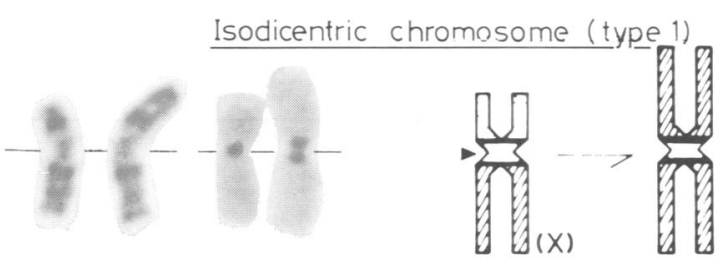

B $\quad 46, X, \operatorname{dic}(X)($ qter $\rightarrow$ p $11:$ p $11 \rightarrow$ qter $)$

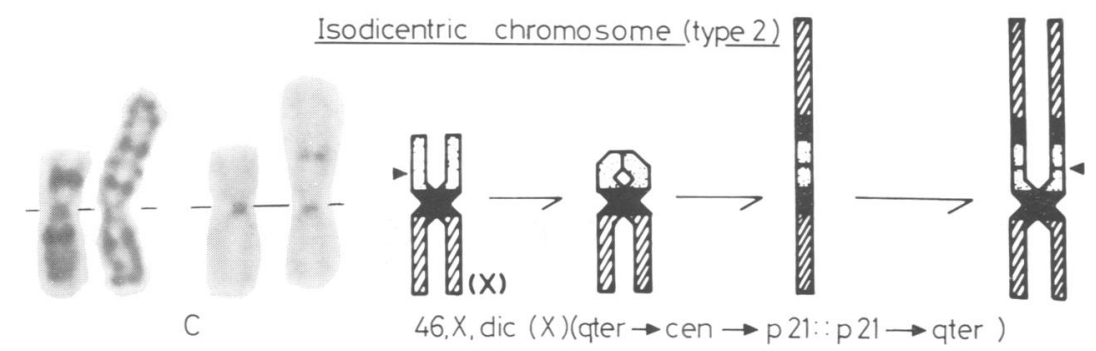

FIG 2 Structurally abnormal X chromosomes. $(A)$ case $3 ;(B)$ case $4 ;(C)$ case 5. 
Case 4 was referred at the age of 20 with a history of primary amenorrhoea and short stature $(145 \mathrm{~cm})$. Secondary sexual characteristics developed normally beginning at the age of 10 .

Case 5 was evaluated at 14 years of age for delayed puberty, short stature, slight webbing of the neck, and bilateral deafness.

\section{Cytogenetic results}

HOMODICENTRIC CHROMOSOMES (FIG 1)

Case 1. Cytogenetic analysis revealed the presence of a structurally abnormal chromosome in all metaphases analysed. The $\mathrm{G}$ banding pattern was most consistent with a structurally abnormal chromosome 16. This chromosome had two $\mathrm{C}$ band regions and was interpreted as being a stable dicentric chromosome formed by breakage and union of two homologous chromosomes. The karyotype is designated as $46, X X,-16,+\operatorname{dic}(16)($ pter $\rightarrow$ cen $\rightarrow$ q $22:: p 11 \rightarrow$ qter $)$. The patient is then trisomic for a portion of the short arm and long arm of chromosome 16 (p11 $\rightarrow$ q22). Parental chromosomes were normal.

Case 2. The presence of an abnormal chromosome 18 was noted on initial $\mathrm{G}$ band analysis. Two $\mathrm{C}$ band regions were present in the abnormal 18 in all lymphocyte and fibroblastic cells analysed. The interpretation of this dicentric is designated as $46, \mathrm{XX},-18,+\operatorname{dic}(18)(\mathrm{qter} \rightarrow \mathrm{p} 11 \cdot 1:: \mathrm{p} 11 \cdot 3 \rightarrow$ cen $\rightarrow$ qter). The patient is then trisomic for the long arm and a portion of the short arm of chromosome 18 (p11 $1 \rightarrow$ qter) and monosomic for a small segment of the short arm (p11 $3 \rightarrow$ pter). Maternal chromosomes were normal.

\section{STRUCTURALLY ABNORMAL X CHROMOSOMES} (FIG 2)

Case 3. The presence of an isochromosome $\mathrm{X}$ with a single $C$ band was observed. The karyotype is designated as $46, X, \mathrm{i}(\mathrm{X})$ (qter $\rightarrow$ cen $\rightarrow$ qter).

Case 4. Three cell lines were present in the patient. An isodicentric $\mathrm{X}$ chromosome was present in two cell lines. This isodicentric $\mathrm{X}$ chromosome had two $\mathrm{C}$ band regions and is identical to the type 1 isodicentric chromosome of Hsu et al. ${ }^{1}$ The karyotype is designated $45, \mathrm{X} / 46, \mathrm{X}, \operatorname{dic}(\mathrm{X})(\mathrm{qter} \rightarrow \mathrm{p} 11: \mathrm{r} 11 \rightarrow \mathrm{qter}) /$ $47, X, \operatorname{dic}(X), \operatorname{dic}(X)$. The proportion of cell types present was $3 \cdot 3 \%, 92 \cdot 3 \%$, and $3 \cdot 3 \%$, respectively.

Case 5 . Two cell lines were detected in this patient: $45, X / 46, X, \operatorname{dic}(X)(q t e r \rightarrow$ cen $\rightarrow$ p $21::$ p21 $\rightarrow$ qter $)$. The abnormal $X$ was observed in $93 \%$ of cells. Two $C$ band regions were present in the abnormal $\mathrm{X}$ chromosome. Because of the presence of asymmetry between the two arms, this would be consistent with the type 2 isodicentric chromosome of Hsu et al. ${ }^{1}$

\section{Discussion}

Homodicentric chromosomes represent a distinctive type of chromosomal aberration described here fox the first time in autosomes. The mechanism op homodicentric chromosome formation may best be understood by comparison with other types of di centric chromosomes (fig 3).

The most common type of dicentric autosoma $\vec{p}$ chromosome is derived from a Robertsonian trans $\overrightarrow{-}$ location. ${ }^{2}$ Most Robertsonian translocations can be interpreted as stable dicentrics possessing one्ड functional centromere and two $\mathrm{C}$ band regions. The

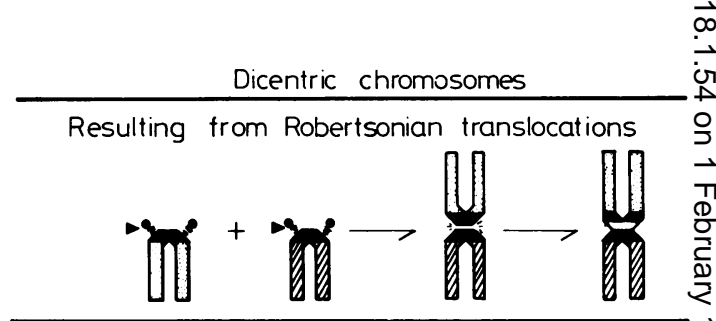

Resulting from non-Robertsonian translocations

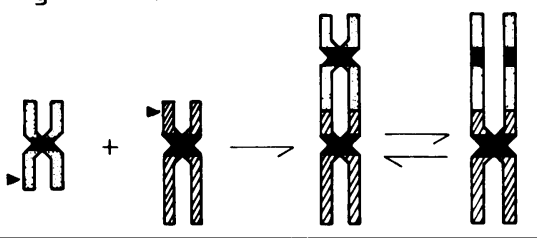

Isochromosomes

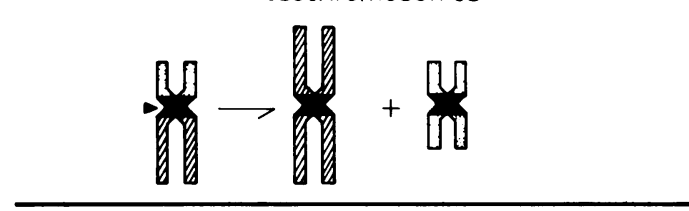

Isodicentric chromosomes
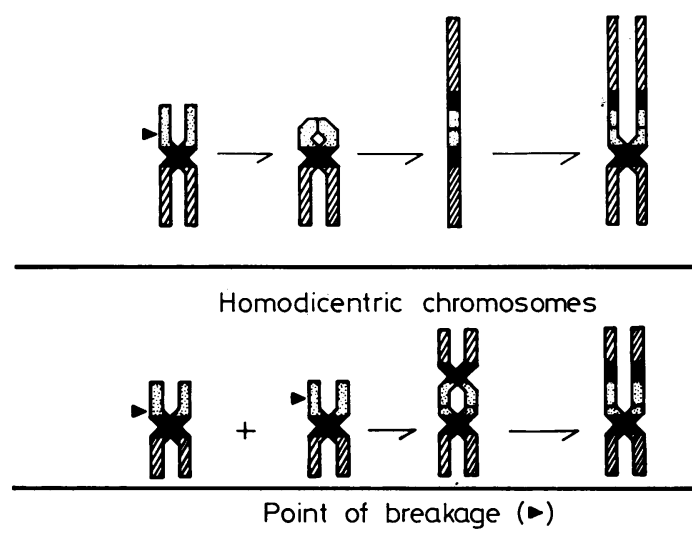

FIG 3 Mechanisms of formation of dicentric chromosomes. 
stability is thought to result from centromere suppression and associated premature division of the suppressed centromere. ${ }^{2}$

Non-Robertsonian translocations involving autosomes have been reported to form dicentric chromosomes. ${ }^{10-12}$ Breaks in non-homologous chromosomes are followed by fusion. The appearance of these dicentric chromosomes may vary in different metaphases from the same sample. When two primary constrictions are observed the dicentric is unstable, and, as a result, is present only in a proportion of cells. If, however, there is only one primary constriction, there is centromere suppression and presumptive premature centromere division of one centromere, and the dicentric then behaves as a stable monocentric chromosome. ${ }^{13}$ The above chromosomes are 'heterodicentric' involving centromeres derived from two non-homologous chromosomes.

An isochromosome is usually formed by misdivision of the centromere, leading to the formation of two metacentric chromosomes in which one arm is the mirror image of the other. Both sex chromosomes and autosomes form this type of isochromosome. Most commonly one of the two isochromosomes is lost, for example, the short arm isochromosome formed by misdivision of the $\mathrm{X}$ centromere. On occasions both long arm and short arm isochromosomes have been observed in the same metaphase. Rarely, an isochromosome is formed by a crossover in a small paracentric inversion loop. ${ }^{14}$

Two types of isodicentric $\mathrm{X}$ chromosomes have been described, those with a point of symmetry between the two $\mathrm{C}$ band regions and those without symmetry. The former situation is presumed to be the result of a break in one arm of a normal $\mathrm{X}$ followed by union of the two resulting centromere bearing fragments. The asymmetrical isodicentric may result from crossover in a paracentric inversion loop or from unequal sister chromatid exchange involving the centromeric region.

Eighty-five percent of isodicentric $\mathrm{X}$ chromosomes occur with mosaicism. ${ }^{1}$ This instability is thought to result from anaphase lag or the formation of an anaphase bridge at first centromere division after isodicentric formation. In subsequent divisions the chromosome behaves as a stable dicentric chromosome with only one primary constriction.

Homodicentric chromosomes occur after breakage in two homologous chromosomes followed by union of the centromere bearing fragments. Evidence that homodicentric chromosomes exist is based on numerous observations. In the cases reported here, the abnormal chromosome is present in non-mosaic state in lymphocytes of both patients and in fibro- blasts of case 2 . The absence of mosaicism is consistent with a meiotic recombination event followed by centromere suppression and premature centromere division (fig 1), preventing the formation of an anaphase bridge on first centromere division. The observed banding patterns are most consistent with homologous chromosome union rather than recombination within a single chromosome, as illustrated by the homodicentric chromosome 16 (case 1) where the banding pattern reveals that portions of two chromosomes 16 are joined to each other in the same orientation. If this abnormal chromosome had arisen from a crossover in an inversion loop or sister chromatid union, one would expect the long arms of the chromosome 16 to be in opposite orientation, similar to that observed in isodicentric $\mathbf{X}$ chromosomes. Wisniewski et $a l^{15}$ have described an abnormal dicentric chromosome 9 presumably derived from union of homologous chromosomes. One of the chromosomes 9 had a large qh region and the resulting abnormal chromosome had two distinctively different types of $\mathrm{C}$ band regions, each being characteristic of one of the chromosomes.

The chromosome abnormalities described in this paper define a new type of structurally abnormal autosome termed a homodicentric, a chromosome similar in appearance to an isodicentric. However, it should be considered as a distinct entity. Unlike homodicentrics, isodicentrics are unstable chromosomes and hence are often present in the mosaic condition.

The homodicentric chromosome is formed during meiosis when there is breakage and union between two homologous chromosomes. Stability in these chromosomes is presumably the result of centromeric suppression and associated premature centromere division, which permits the formation of a stable, functionally monocentric chromosome. The lesion results in a duplication-deletion syndrome.

\section{References}

1 Hsu LYF, Paciuc S, David K, Cristian S, Moloshok R, Hirschhorn K. Number of C-bands of human isochromosome Xqi and relation to $45, \mathrm{X}$ mosaicism. $J$ Med Genet $1978 ; 15: 222-6$.

2 Daniel A, Lam-Po-Tang PRLC. Structure and inheritance of some heterozygous Robertsonian translocations in man. J Med Genet 1976;13:381-8.

3 Daniel A, Saville T, Southall DB. Further dicentric $X$ isochromosomes and deletions, and a new structure $\mathrm{i}(\mathrm{X})(\mathrm{pter} \rightarrow \mathrm{q} 2102 \rightarrow$ pter $)$. J Med Genet 1979;16:278-87.

4 Arakaki DT, Sparkes RS. Microtechnique for cultured leukocytes from whole blood. Cytogenetics $1963 ; 2: 57-60$.

5 Hungerford DA. Leukocytes cultured from small inocula of whole blood and the preparation of metaphase chromosomes by treatment with hypotonic KCl. Stain Technol $1965 ; 40: 333-8$. 
${ }^{6}$ Ham RG, Puck TT. Quantitative colonial growth of isolated mammalian cells. In: Colowick SP, Kaplan NO, eds. Methods in enzymology. vol V. NewYork: Academic Press, 1962:90-119.

7 Seabright M. A rapid banding technique for human chromosomes. Lancet 1971 ;ii:971-2.

8 Arrighi FE, Hsu TC. Localization of heterochromatin in human chromosomes. Cytogenetics $1971 ; 10: 81-6$.

9 Caspersson T, Zech L, Johansson C. Analysis of the human metaphase chromosome set by aid of DNAbinding fluorescent agents. Exp Cell Res 1970;62:490-2.

10 Funderburk SJ, Sparkes RS, Klisak I. 18p - syndrome resulting from $14 \mathrm{q} / 18 \mathrm{q}$ 'dicentric' fusion translocation. Hum Genet 1977:39:243-50.

11 Sekhun GS, Hillman LS, Kaufman RL. Identification of a 19/20 translocation by $G-, Q-$ and $C$-banding. In: Bergsma D, ed. New chromosomal and mutational syn- dromes. Birth Defects 11, No 5. New York: The National Foundation-March of Dimes, 1975:237-40.

12 Singh-Kahlan DP, Serra A, Bora R. A complex mosaic with $\mathrm{D} / \mathrm{E}$ translocation $\operatorname{tdic}(15 ; 18)(\mathrm{p} 12 ; \mathrm{p} 11)$ in an oligospermic male with apparently total infertility. Clin Genet 1977;11:342-8.

13 Daniel A. Single Cd band in dicentric translocations with one suppressed centromere. Hum Genet 1979;48:85-92.

14 Priest JH, Blackston RD, Au KS, Ray SL. Differences in human $\mathrm{X}$ isochromosomes. $J$ Med Genet 1975;12: 378-89.

15 Wisniewski L, Politis GD, Higgins JV. Partial tetrasomy 9 in a liveborn infant. Clin Genet 1978;14:147-53.

Requests for reprints to Professor Arthur Robinson, National Jewish Hospital and Research Center, 3800 East Colfax Avenue, Denver, Colorado 80206, USA 